\title{
DOING A DOCTORATE IN BUSINESS ADMINISTRATION: THE CASE FOR CRITICAL REFLEXIVITY
}

\begin{abstract}
This paper focuses upon the value of critical reflexivity in illuminating practice-based management inquiry. Drawing upon contributions to debates in the field, the paper demonstrates how critical reflexivity permits interrogation of the dynamic tensions associated with 'real life' practice and scholarly research on Doctor in Business Administration (DBA) programmes. It offers clearer understanding of the complex journeys undertaken, greater recognition of the organizational and cultural landscapes inhabited, and broadens concepts of how 'success' on DBA programmes may be evaluated. The paper further argues that critical reflexivity plays a key role in highlighting the various processes underlying the design, management and delivery of DBA programmes. In this way, the paper offers useful insights likely to be of interest not only to taught doctoral students in the field but also academics involved in developing practice-based management programmes in higher education. The paper's arguments are developed using a qualitative methodological approach underpinned by two primary data sets collected from different cohorts of students on DBA programmes and secondary sources subject to retrospective content analysis.
\end{abstract}

Key Words: Critical Reflexivity; Doctor in Business Administration; Professional Doctorate. 


\section{INTRODUCTION}

It has long been argued by management educators that merging theory and practice will result in better theory and better practice. Over a decade ago now, Raelin (2002; 2007) and Van de Ven (2007) maintained that scholarship and 'real life' practice were separated by thinking underpinned by Cartesian logic which should be challenged. This paper argues that scholarly contributions to both theory building and practice development are an essential component of many professional doctorate programmes in the field of management education (Klenowski and Lunt 2008). Taking as its focus the Doctor in Business Administration (hereafter DBA) programme at a higher education institution in the UK (hereafter given the pseudonym SWAN), it is argued that critical reflexivity is key to deepening our understanding of how theory informs practice and practice informs theory. This is of relevance to this particular doctoral programme because DBAs are distinct from other forms of doctorate, especially the traditional doctor of philosophy (PhD), in terms of their structures, relationships between students and programme teams, and management of student studies.

Since its inception, the DBA programme at SWAN has emphasised the requirement for students to be critically reflexive (Cunliffe 2011; Gray 2007) in terms of their theoretical, workbased and research practices. But with notable exceptions (Dent 2002), inquiries into how critical reflexivity contributes to the distinct 'doctoralness' of DBA programmes is lacking. The paper does not seek to articulate how critical reflexivity should be incorporated into or taught on DBA programmes. That undertaking has strong precedents in the work of others (Cunliffe 2004; Klenowski and Lunt 2008). Here the focus is upon the value of critical reflexivity in illuminating a ‘scholarship of practice’ (Ramsey 2014), specifically in relation to systematic analysis of the DBA student experience and the DBA programme team input. 
Consideration of the role of critical reflexivity is crucial in terms of not only providing a grounded exploration of the various perspectives of DBA students but also illuminating the processes underlying DBA programme design, delivery and management. DBA students are expected to establish when, how and why their research makes a difference to the businesses and organizations in which they work and identify their contributions to knowledge and understanding. In short, it is incumbent upon them to become critically reflexive scholarly practitioners. That requirement can also be extended to academic staff as management educators, primarily in terms of considering how and what they input into the DBA programme over time and how they constitute and shape relationships between DBA programme teams and DBA students. As Raelin (2007: 498) argues: ‘... by immersing management students in a protracted period of study prior to entering the profession, management would be in a better position to assert its legitimacy'. Undergoing a high level 'protracted period of study' is clearly not the sole aim or outcome of taught doctoral programmes in management education. A review of debates in the field of critical reflexive management inquiry and practice and their particular relevance to the DBA, follows.

\section{LITERATURE REVIEW}

\subsection{Critical Reflexivity}

Reflexivity is concerned with questions about researchers as agents in a situation, whereas, reflection is concerned with questions that they may have about a phenomena (Hibbert et al, 2010). Both are important for both academics and practitioners alike. Conventionally, reflexivity has been identified by Bettany and Woodruffe-Burton (2009: 661) as: ‘...a way to give insightful commentaries into the research process itself'. On the other hand, rather than simply offering insights into methodological issues, critical reflexivity involves: ‘...turning a 
self-critical eye onto one’s own authority as interpreter and author' (Alvesson and Sköldberg 2009: vii). Cunliffe (2004: 407-8) has defined critical reflexivity as meaning, in practical terms: '...examining critically the assumptions underlying our actions, the impact of those actions, and from a broader perspective, what passes as good management practice'. More than this, she also argues that: 'the practice of critical reflexivity is particularly important to management education because by thinking more critically about our own assumptions and actions, we can develop more collaborative, responsive and ethical ways of managing organizations' (2004: 407-8). Critical reflexivity also involves exposing contradictions, doubts, dilemmas and possibilities (Hardy and Palmer 1999). This has particular relevance for DBA students where implications for professional practice require systematic consideration of their potentially conflicting roles within academic, organizational and business life (Cunliffe 2002, 2003; Hibbert et al 2010).

But the matter goes deeper than this. Raelin (2007: 496) has argued that: 'the dominant empiricist epistemology governing our educational enterprises in higher education as well as in corporate training and development leads us to separate theory and practice in an aspiration to define the best conceptual models to map external reality' (496: emphasis added). It could be argued that in terms of mapping relations between theory and practice, undertaking a professional doctorate such as the DBA potentially addresses this problem and results in more ‘engaged scholarship’ (Van de Ven 2007). By means of developing critical reflexivity in both contexts then, many DBA programmes in higher education are explicitly designed to offer a bridge between theory and practice. Ramsey (2014) identifies three domains of attention: 'an engagement with ideas, a practice of inquiry and a navigation of relations' (2014: 6-7) and argues for: 'a scholarship of practice that centres intentional attending-to as its core'. These aspects are central to the DBA programme at SWAN. Given this, it is incumbent upon those involved in the DBA, both as students and academics, to engage with debates on critical 
reflexivity in business, management and the social sciences (Conklin et al 2013; Keevers and Treleavan 2011; Paton et al 2014; Vince 2002). That is what this paper sets out to do in terms of specifically addressing how critical reflexivity informs practice-based management education. The next section turns to discussion of the development and status of professional doctorates more generally.

\subsection{Professional Doctorates and the DBA}

The UK's Quality Assurance Agency (QAA) describes a doctorate as having: 'common currency globally as the highest academic qualification a university can award' (QAA 2011: 5). Historically, a doctorate has been the 'gold standard' (Ruggeri-Stevens et al 2001: 61) in respect to higher education awards in the UK and elsewhere and has been awarded for an original contribution to knowledge made by the candidate's work. Traditionally, the $\mathrm{PhD}$ in the UK has followed an apprentice/master model but since the early 2000s, doctoral programmes have incorporated research methodologies and generic skills training (see for example, the Quality Assurance Agency’s Characteristics Statement - Doctoral Degree 2015). This expansion or diversification has been a response to the changing loci and a wider appreciation of what constitutes a doctorate. There are now a range of different forms of attaining a doctorate, including the PhD by publication (Costley and Lester, 2010; Usher 2002). Doctoral level qualification is increasingly sought in professional areas, beyond and outside of academia. As such, UK higher education has developed a portfolio of alternative forms of doctorate such as the professional and practice-based (or practitioner) doctorates. Although some have identified differences in the delivery and assessment between different doctoral awards (Bourner et al 2000; QAA 2011), the fundamental difference between a PhD and a DBA lies in the contribution to knowledge. As the QAA (2008) states: 'the DBA has a dual 
purpose - to make a contribution to both theory and practice in relation to business and management, and to develop professional practice through making a contribution to professional knowledge'.

Undertaking a practice-based professional doctorate such as the DBA is often the choice of doctoral pathway for mid-career professionals. As senior practitioners in their field, DBA students are used to identifying and dealing with various 'real life' issues. They expect policy and practice within their organizations will be improved in light of their doctoral research and recognise that in investigating 'real life' problems, they (and their organizations) will undergo transformative change. But taking a 'solutions' approach to organizational problems is not in itself sufficient for success on the DBA. A detailed knowledge and understanding of doing original research has to be central. How to empower students to situate and analyse all this within sophisticated, rigorous and scholarly frameworks is something that the DBA programme team at SWAN have addressed in the design and delivery of the programmes over the last two decades. In what follows, the paper explicates how a critical reflexive approach to interrogating these issues shaped academic thinking on the DBA over time.

The antecedent of the DBA at SWAN was a guided doctorate programme set up in 1996 with the first graduates being awarded from 2000. This programme comprised a variety of modules rooted in the philosophy, ethics and practice of doing research and included subject-based modules including leadership. The programme concluded with the production of a major research dissertation. The approach was informed by the US doctoral tradition that has taught subject based courses culminating with a comprehensive examination or examinations that tested breadth rather than depth of knowledge. At SWAN, after two cohort deliveries, the original guided doctorate programme was revised as a result of staff and student feedback which indicated that the subject-based approach did not fit well with the emergence and development of a topic-based thesis. The redesigned programme was based on methodological 
and methods modules and a significant thesis. The programme was revised again in 2008 and a new 'stepping stone' or 'building block' version was designed. This current structure, while retaining the focus on methods, is much more focused on student progression in terms of the accumulation of credits from taught modules and the development of chapters which lead to completion of the thesis.

Within each iteration of the award, the DBA development team sought to ensure that the outcome of the programme was achieving the dualism of contributions to both knowledge and practice. The DBA programme at SWAN is now systematically structured as a 'stage-bystage’ process. Once applicants have submitted an initial research proposal, are interviewed and appropriate Directors of Studies (hereafter DoS) and second supervisors allocated, they are formally accepted. They undertake five consecutive modules with credits attached to each. All modules are clearly centred on assessments which then form specific chapters of the completed thesis. Delivery takes place in 2-3 day workshops and recall ${ }^{1}$ sessions. Drawing upon critical reflexive understanding of how this structure works, assumptions underlying the current DBA programme at SWAN can be identified and interrogated. One basic assumption is that an upward, sequential movement takes place, from the 'pure’ practitioner embarking upon Module 1 to the 'expert' academic researcher emerging from Module 5. This assumption requires and receives critical consideration in the data analysis section of this paper.

In terms of re-developing the programme over time, the DBA academic team recognises that the organisation and management of the programme requires particular forms of engagement between staff and students. Students and their supervisors are unlikely to conform to the traditional apprentice/master model of undertaking a doctorate. DBA students are often mature professionals whose career progression from 'novice' to 'expert' is unlikely ever to have been

\footnotetext{
${ }^{1} \mathrm{~A}$ recall session is where a student returns a few months after the module workshop and presents progress, issues for peer review.
} 
or still be an uncomplicated undertaking. In some respects, many DBA students embarking upon the first stages of the DBA programme will already be more 'expert' on certain matters than those designing and delivering the taught modules. In acknowledgement of this 'peer-topeer' interaction, the SWAN-based DBA administrator organizes 2-3 day block deliveries to include informal lunches, drinks receptions and dinners held in local city restaurants. These social gatherings are usually attended by both DBA students and the DBA programme team as well as some of the DoS and second supervisors. This collective, less-hierarchical initiative is not typical or standard in the traditional $\mathrm{PhD}$ student experience. But while the autonomy and authority conferred upon DBA students can arise from their substantial organizational and/or management experience, nonetheless they are still by definition, early or novice academic researchers. As Brooks and Coombs (2010) noted in an early DBA Award Handbook, such students are often already 'working professionals' employed full-time at senior levels in organisations across a range of private, public and third sectors in the UK and abroad. Questions about how to address the relations between professional practitioners and academic researchers, and by extension the balance between theory and practice, are therefore pressing concerns and the argument here is that critical reflexivity is key to these inquiries.

In the course of undertaking the DBA, students have to develop awareness that they must question what they have learnt from the research process itself and how this might enhance their professional development. Critical reflexivity is therefore central in making original contributions to knowledge and practice on the DBA and this differs from the contribution made by traditional PhDs. The traditional doctoral thesis involves thinking alone, taking an original standpoint position or 'place' in the cannon, often by refuting the position of others. Issacs (1999) has argued for the development of collective leadership and partnership learning which embraces different viewpoints and avoids the 'winner-loser' structure of argument and debate. This is reflected in the 'dialogic spaces' which Isscas (1999) sees as analogous to the 
field of nuclear physics in which atoms move around, with many simply flying past one another whilst others collide and cause friction. On the DBA programme at SWAN, the interrogation of the various constituents of these ‘dialogical spaces’ (Issacs 1999) is fundamental for success on the programme. The paper turns now to review the context in which critical reflexivity in relation to professional doctorates has developed. This will provide the background for the data collection and data analysis which follows.

\subsection{Critical Reflexivity and the DBA}

In exploring the potential of the DBA to improve reflective and reflexive abilities, particularly in areas of creativity, analytical skills, communication and strategic thinking, Williams (2010) maintains that these have not always been clearly identified by those working in the field. In exploring its operationalization, Mauthner and Doucet (2003) discuss critical reflexivity in terms of four influences (personal, interpersonal, emotional and pragmatic) on fieldwork research and data analysis processes. They also show how epistemological and ontological positioning can be translated into research practice, thereby contributing to current debates which aim to bridge the gap between the nitty-gritty of research practice and abstract epistemological discussion. But while it is relatively straightforward to give DBA students advice and guidance in terms of pragmatic methodological issues, empowering them to become critically reflexive researchers is a more complex process. This is complicated by the requirement for DBA programme teams to also subject themselves and their work to critical scrutiny.

In the process of doing so, basic assumptions can surface. The DBA award handbook at SWAN claims that: 'participants develop a high level of independent and critical thinking through a programme of research based upon real issues facing their organizations' (Brooks and Coombs, 2010). Central to this claim is the requirement for DBA students to continually interrogate 
their experiences of conducting research, to reflect upon their practice, to identify the underlying issues which have resonance for them and engage in forums in which difficult issues can be raised, discussed and resolved. It is clear that DBA students constitute a critical case for investigation of these issues, not least because, as argued earlier, they constitute a distinct and different student body from more traditional full-time $\mathrm{PhD}$ students undertaking research often with the intention of entering academia. Unlike some more traditional $\mathrm{PhDs}$, those who enrol on the DBA programme at SWAN are expected to undertake high quality research which makes a significant difference to their working lives and to the organizations in which they are based. In this respect, the dynamic tension between being and becoming research-practitioners and academic 'experts' is opened up to scrutiny from the beginning of their studies. It is this dynamic that drove the data collection and data analysis undertaken for the paper.

\section{DATA COLLECTION}

The paper has already drawn upon secondary data in the form of DBA award handbooks, module specifications and formal guidance. All these underpinned the retrospective analysis of the various iterations of the DBA programme at SWAN as outlined earlier. To probe the role that undertaking the DBA plays in students becoming critically reflexive researchpractitioners, the primary data collected for this paper was framed in terms of encouraging students' responses to a range of questions centred on the relationship between being and becoming professional practitioners and academic researchers. These questions were raised in different settings using various methodological tools, including online questionnaires and focus group discussions, both of which were designed to encourage students' own utterances. In order to furnish this analysis, the paper draws upon two distinct but overlapping primary data

sets. The first primary data set comprises written responses to a self-completion, online 
questionnaire distributed to and completed by fifteen participants between February - March 2014. This group contains students who have completed their DBA $(n=2)$ or transferred to $\mathrm{PhD}(\mathrm{n}=1)$; students enrolled on Module 5 and/or near-completion ( $\mathrm{n}=7$ ); students enrolled on or starting Module 4 in April $2014(\mathrm{n}=3)$ and students starting Module 2 in April 2014 (n = 2). For analytical purposes, we refer to these students as the questionnaire respondents (hereafter QR). The second primary data set was collected by means of transcribing the responses from a focus group consisting of eleven participants. Participants were asked about the value of the doctorate, its impact on their employment and the extent to which it provided new skills of analysis and reflection. Respondents were keen to be involved in this research as they were keen to inform the authors about the value of their doctorate, on areas of their life including employment and beyond. There was no overlap between the focus group participants and the questionnaire respondents above. The profile of the focus group also included those at various stages of the DBA and for analytical purposes, we refer to this group as the focus group participants (hereafter FGP).

\section{DATA ANALYSIS}

Data analysis proceeded by a multi-layered and thematic analysis of various 'talking points' which arose in both data sets, thereby allowing key issues to be identified and wider arguments to be developed. Insights into the processes, outcomes and impact of undertaking the DBA were developed by the use of a critical reflexive lens with which to make sense of, contextualize and present those various 'talking points' under four distinct but overlapping thematic categories. The four inter-related themes identified and developed in the data analysis are introduced briefly and then discussed under separate sub-headings below. First, undertaking the DBA as a complex 'journey' is apparent in the data and is seen by many 
respondents/participants as typical of the student experience on the DBA. Second, what students think of 'doing' the DB is also apparent in the data. Analysis proceeded by organising these utterances in terms of what is seen as positive and negative. Third, the complex 'clashes' between practitioner and academic workplace cultures is also apparent in the data. Fourth, what constitutes success in terms of the DBA is also apparent and receives critical appraisal in terms of broadening understandings of 'success'.

\subsection{The DBA as 'Journey'}

In order to explicate this theme, analysis of what motivates DBA students to embark upon the DBA programme highlights the importance they attach to filling or bridging gaps in terms of academic status and standing. As one FGP student claimed, there was:

...not much of history of people educated in management in (name of public service organization) so I wanted a strategic management qualification.

But whilst some students expected that achieving a professional doctorate would secure greater rewards and prestige, for many it was the 'journey' itself that mattered. As another FGP student explained:

For me having a DBA appearing prestigious wasn't important. (The) programme and self-journey are the motives. The importance of this programme is the way practitioners are developed rather than linking it back to some theoretical ranking.

Such developmental 'journeys' can often appear at the outset to be unknown and unmapped, hence this appears to support the DBA team's development of the 'building block' structure on the current programme. An underlying assumption here is that this 'stage-by-stage' approach develops and supports DBA students' critical reflexive skills over time. Despite this, many respondents/participants identified difficulties in understanding what was required of 
them as they progressed through the various modules. Furthermore, while strong emphasis is given by the DBA team to providing students with clear directional sign posts, for many respondents/participants dealing with the challenges and demands encountered en route was spoken of as a personal, and to some extent, private trouble. As one QR student enrolled upon Module 4 explained:

To a large extent, in the early stages, it is almost part of the rite of passage that you have to work it out yourself.

This throws into question assumptions made by the DBA team in terms of what the process involves. Rather than students undertaking a structured programme with clearly delineated 'stepping stones', several of them spoke of experiencing their 'journey' as one of being left on their own to struggle. Even when specific goals are achieved, this was still viewed as an ad hoc and personal undertaking rather than a strongly supported, collectively shared process. As another near-completion QR student put it:

As the process develops, you learn more, you develop skills and confidence, and you also begin to develop in depth expertise in your subject area which makes research easier, as you have a clear idea of who the key authors are, what the prominent discourses are etc, so almost by osmosis you begin to learn.

Such tropes ('rites of passage', 'learning by osmosis') suggest that DBA students experience the process of undertaking the programme as a series of implicit rather than explicit achievements. Linked to this, many respondents/participants also identified the development of their own problem-solving strategies as important to their 'journey'. These ranged from improved self-management of their own learning to support-seeking from others, including their DoS and supervisor(s), colleagues/managers in their own organizations as well as family and friends. 
But analysis of student responses do call into question any expectations that the DBA team may have had with respect to students undertaking a seamless, sequential and supported pathway through the programme. In particular, it is clear that there is little or no (if there ever was) upward or linear movement from the ‘pure’ practitioner embarking upon Module 1, to the 'expert' scholarly researcher emerging from Module 5. Data analysis indicates that students experiences of undertaking a DBA are much more fluid, fluctuating and contingent than any 'building blocks' approach might suggest. In the light of this, there is an argument for not measuring DBA outcomes only or solely in terms of producing set pieces of assessed work leading to successful completion. More than this, making easy assumptions about the level of critical reflexive abilities that are developed by individual students as they progress sequentially through the programme are also problematic.

\section{2. 'Doing' the DBA}

Further data analysis permitted a second and related theme to surface. The identification of an unknown (but not unknowable) 'journey' through the DBA calls into question what students think and say they are 'doing'. To further unpick the complexity here, the undertaking of the DBA programme, particularly in relation to negotiating the tensions between professional practice and academic research, requires explication in terms of its positive aspects. One positive benefit can be seen in the response of a QR student about to undertake Module 2, who stated that:

the combination of practitioner and researcher is an optimal way of conducting doctoral research. It promotes the realistic nature and applicability of research in the real world. The doctoral researcher will have direct access to data and already is a practical and semi academic expert in their research field. So, he or she is daily working as a practitioner and as a doctoral student... 
The integration of professional practice and academic research in terms of creating a productive interplay between the two, is seen by many respondents/participants as very beneficial. For example, another QR student about to embark upon Module 4 claimed that:

There is a strong correlation between my day job and the doctorate. My research is focused at solving a practical problem. The research results will not only help me but other practitioners in the field.

Similarly, an FGP student enrolled on Module 4 commented in relation to the positive benefits of negotiating the practitioner-researcher dynamic:

...it has been seamless as it is integrated into my work and I talk to them (work colleagues) all the time when it comes to my data collection. It is something that isn't separate from my day job...

The 'vantage point' of becoming a fully integrated practitioner-researcher is especially valued by several students who are near-completion or have completed Module 5, particularly in terms of reflecting upon their research design and fieldwork data collection. One QR student who had completed the DBA, reflected upon this beneficial engagement as follows:

As a doctoral degree, academic credibility was of paramount importance. Where being a practitioner helped was in the identification of a relevant research question, access to data (in my case I surveyed and interviewed customers of eight leisure centres which were under my management control, this access would not have been given to an outsider) and the ability to write about how your contribution to knowledge would/could be used in an organisational setting.

The benefits of developing the necessary competencies to make theoretical sense of 'real life' organizational issues are thus seen as productive and positive by many respondents/participants. More than this and particularly amongst those students nearing completion, there were claims that their doctoral research is already having a powerful impact 
upon the organizations in which they work. As one QR student at this stage explained:

I think my research has led to changes in both policy and practice. I'm carrying out research on a moving target with my research informing changes in policy and practice that I then research. This means that the doctoral work is enormously beneficial to organisations, but that the standpoint/context of the researcher changes as their research influences the organisation.

Hence for these students, the integration of professional practice and academic research appears to be, in the words of a QR student enrolled on Module 5 and near-completion:

...symbiotic - each strongly supports the other. The practice clearly benefits from a grounding in theory and support from historic evidence, while the practice helps to make the theory come alive, and provides guidance for the profession.

It can be argued that 'doing' the DBA has thus enhanced the ability of many students to critically examine their involvement with practice as informed by extant relevant theory. Others also spoke of the positive aspects of feeding back and forth between their academic research and professional work environments. They spoke of the development of various business and management skills, including appraising people and situations more critically, making better evidence based decisions, arguing more effectively, and the ability to more easily focus upon what was important. Some students saw themselves as catalysts, rolling out and leading on evidence-based decision making in their organisation. One FGP student for example claimed that there were clear benefits in terms of:

Making other people better practitioners, if you are in a senior role looking to convince other people... and to provide evidence based ideas to support arguments around practice.

All this also points to critical reflexivity as a key element in the development of the students' understanding and experiences of 'doing' the DBA. 
In contrast however to those for whom there was little difficulty in negotiating professional practitioner-academic researcher dynamics, for some DBA students such tensions were highly problematic. Bearing in mind the first analytical theme concerning the ways in which students experienced the DBA as a 'journey' in which they found themselves struggling by themselves and/or getting easily lost, it is not surprising that for several of them, the dynamic tension between professional practice and academic research was spoken of as constraining and even at times, overwhelming. Finding a balance between academic research and professional practice is clearly a serious challenge and for some, the 'gap' is almost unmanageable. This presented several students with major difficulties in terms of progressing their research towards any kind of successful outcome. As one QR student who was enrolled on Module 4 stated:

...you shift from one state to another when there is time...this is the most difficult part of the work. I find that when I can focus on my (DBA) work I am in the zone... in my job, the (DBA) work has informed my thinking and approach. I suppose ideally the two become one and a hybrid emerges at the end. But my (DBA) work is at the fuzzy boundary between the two and that can be tricky... a practitioner/researcher, one pays the bills the other feeds the mind...

This is not to suggest that the 'gap' between professional practice and academic research is problematic for this student alone (although clearly it is), but that making sense of the dynamic tension between the two does need to be addressed in terms of both its complex relationship to critical reflexivity. As an index of this, several DBA students talk not only about the ways in which business and organizational ‘drivers’ are different from academic protocols, but can also be counter-productive in relation to achieving 'successful' outcomes on the DBA. As one QR student enrolled on Module 5 explained:

I was not really motivated by the opportunity of achieving the qualification itself, and perhaps this is why, having completed the research (but not the thesis), I find motivation to completion difficult. Also, the contribution to practice has been a huge success, with various aspects of my work being taken up by major corporations. Whilst this has been very satisfying, it has perhaps reduced my motivation to complete the thesis. From a 
practitioner perspective, events have somewhat overtaken the value of 'crossing the finishing line'.

For several DBA students then, there is a strong recognition that the demands of 'doing' the

DBA are complicated by the wider business and organizational environments in which they operate. This does not necessarily cohere with assumptions made by the programme team about designing the DBA to be a relatively straightforward goal-orientated process. This is partly because 'real life' in the business and organizational domain is viewed as demanding, greedy and unpredictable. As one QR student who was near completion, commented that:

Work commitments are not in my control; they are affected by the requirements of the minister, department, media etc. There is no solution to overcome external factors you just have to work around them.

But more than this, addressing such problems tends to be viewed by many DBA students as requiring more than simple logistical problem-solving skills or effective time-management strategies on their own behalf. The competencies and skills needed in the professional practice and academic research domains were often spoken of by students as 'at odds' and sometimes in direct conflict with one another.

\subsection{Organizational Cultures}

Further analysis of the data reveals a third inter-related thread, namely that such 'clashes' can be attributed to the different rationales and ethos of private business and/or public service management on the one hand and the academy on the other. As one of QR student about to undertake Module 2, stated:

A business approach does not always strike (sic) with an academic way of analysing occurrences.... This can be in conflict with acting in the daily business world, where the need to act is more important that the need to understand. 
Similarly, dealing effectively with the challenges of acting/understanding was seen by another near-completion QR student to be especially complicated by differences in organizational cultures across the various private, public and academic sectors inhabited by DBA students:

Having been in business as a senior civil servant for a number of years, returning to a more thorough, academic approach to backing up every statement with a solid line of reasoning, with appropriate evidence is challenging. In business, one quickly falls into using persuasive 'marketing' language, rather than evidence, to make a point, and gain success. And if you are good at this, then you become very lazy, because success comes easily. Getting back into a more solid 'reasoned' approach required practice and continuous conscious effort.

The difficulty of straddling organizational cultures with varied and sometimes conflicting requirements was also captured by a QR student who had recently completed the DBA, and who pointed to how:

...developing an academic writing style - this was difficult but even more so when you had to revert back to a managerial writing style whilst at work. My manager frequently asked me to stop justifying everything I said/wrote in my e-mails and memos...!

By employing a critically reflexive 'lens' with which to focus on the different organizational contexts in which DBA students are located, an argument can be developed that the DBA ‘journey’ cannot be successfully undertaken by individuals acting alone. The first theme in the data analysis pointed to a tendency for DBA students to see the difficulties they encountered on their DBA journeys as private struggles rather than collective endeavours on everyone's part. The comments made by a QR student who was starting Module 4, illustrate this point:

The research process at this level is agonisingly hard in some parts, especially the philosophical positioning of the work. I am still not sure about what my work is discovering and that can be a bit dispiriting. I believe that I was told that at this level you become a significant expert in your field. If like my work, it is emergent, it can be a bit of a lonely task and the end point seems a long way off. 
This approach to doctoral study being the sole endeavour of a single individual in pursuit of originality, is more typically the benchmark of a traditional $\mathrm{PhD}$. As professional practitioners however, DBA students inhabit complex, challenging and often conflicting landscapes with very different route markers. At times they are required to be critically reflexive in terms of their own actions as an agent within a professional arena, while at other times they are expected to demonstrate sophisticated understanding of academic scholarship as applied to their professional practice. It is not surprising that many of them identify difficulties in integrating an academic research orientation with a business or professional practice modus operandi. Managing the demands of the academic while not losing sight of the practice has long been seen as challenging for students who are embarking upon the DBA (Green and Powell 2005; Maxwell 2008). But on the basis of the data analysis undertaken here, it is apparent that 'success' is inevitably problematic in terms of the DBA 'journey' being organizationally, culturally and collectively fraught with tensions. These dynamics often only reveal themselves over time. As an index of this, several near-completion students identified real difficulties in fulfilling the DBA programme requirements precisely because of the cultural and historical 'clashes' between academic research and professional practice. Comments from one nearcompletion QR student identified their dilemma as follows:

... having confidence in my ability to become an effective researcher. Understanding how to do this from academic rather than a professional perspective was difficult as the two are very different disciplines.

Another near-completion QR student captured the problem even more succinctly. In this student's view, they identified having a:

... lack of experience in academic rigour, because this is not a skill that is a prerequisite for the public service. 
This further illuminates the first theme discussed and points to the DBA being even more of a winding and confusing 'journey' marked by confusing and sometimes conflicting organizational and cultural 'signposts'. Not surprisingly, such complexity can lead DBA students to not only lose sight of the end goals or exit points, but also question the whole DBA process in terms of where they are, what they are doing and what they are seeking to achieve. In all this, critical reflexivity becomes ever more important and valuable in helping students find ways through this difficult terrain. Even more crucially, recognising the value of and developing such critically reflexivity in order to make sense of the shortcomings and obstacles they encounter is not a 'failure' on the part of DBA students but is absolutely critical to their success on the programme. This leads to discussion of the fourth and final theme identified in the data analysis.

\section{4. 'Success' on the DBA}

It is important in supporting the case for critical reflexivity, to note that the complexities encountered in the process of undertaking the DBA are better understood as students approach completion. As one QR near-completion student commented in relation to grasping what was required of them, it was:

...understanding the huge step change required, the link between the components being studied and it was only after the third assignment that the penny really dropped...

Another near-completion QR student similarly explained how: 
Organisation and management of research material has been a skill that I have acquired en route, largely through practice. By reading a large number of papers you can gain 'an eye' for what is sound or weak, what is pertinent or just interesting to read. This has been a rewarding achievement that I am using in other branches of my work to great benefit.

There are clear benefits to students in undertaking the DBA not simply in order to become academically successful per se, but also to develop as 'engaged scholars' in terms of the processes they have undergone en route. The data analysis shows that the underlying processes identified and explored are not simply a matter of the incorporation of different or even opposing elements of academic research and professional practice. Viewing the professional practitioner-academic researcher in this way, namely as opposing or binary tensions in the lives of DBA students, is not helpful. Instead, the complexities spoken of by students can be better viewed as productive of 'success' in terms of DBA outcomes, dependent as they are upon wider understandings of the dynamic processes undergone. More than this, it can be argued that many students experience 'success' on the DBA as much in terms of providing them with the necessary competencies to operate more effectively within the practitioner environment, as they do in terms of achieving outcomes measured largely by academic 'results', the accumulation of credits and the award of a DBA. This opens up possibilities for re-visioning what 'success' might mean for students 'doing' the DBA.

\section{CRITICAL REFLEXIVITY REVISITED}

This section of the paper revisits the contribution of critical reflexivity and reflects upon the design, delivery and forward direction of DBA programmes at SWAN and elsewhere in the light of the data analysis undertaken. Much has been written about the value of critical reflexivity for organizational researchers (Alvesson et al 2008; Cunliffe 2011; Hibbert et al 
2010; Johnson and Duberley 2003; Rhodes 2009). One of the drivers on DBA programme has been the recognition that more emphasis needs to be placed on students becoming critically reflexive practitioner-researchers (Gibb et al 2012). In this, it is vital that DBA students question the wider 'real life' environments within which they operate and foster dialogue between all relevant stakeholders, both in academic and professional practice networks. There are precedents for this, as can be seen in the work of Orr and Bennett (2009) who draw upon personal experience of designing and conducting a research project into management learning, run jointly between an academic and a senior practitioner. The dynamics of research collaboration are considered in detail and Orr and Bennett (2009) argue that critical reflexivity helped to produce insights into a process which they refer to as one of 'co-production'. It is to this notion of co-production and its relevance for critical reflexivity on DBA programmes at SWAN and elsewhere that the discussion now turns.

Hardy et al (2001: 531) have argued for: ‘...a reconceptualization of reflexivity in organization and management theory, which moves beyond the common view of heroic individuals struggling to understand and manage their role in their research towards an understanding of reflexivity as involving the research community as a whole' (531: emphasis added). The value of developing critical reflexivity as a collective endeavour underlies the data collection and data analysis undertaken here, involving as it does, ongoing and direct engagement with DBA students by the DBA programme team. This co-production in terms of enhancing understandings of what is involved in doing the DBA can be beneficial to a range of academic and practitioner communities. But while there have been calls for the DBA to gain greater prominence as a valuable qualification in its own right, raising the awareness of its contribution to the development of practitioner-researchers who are highly critically reflexive in both theory and practice has been less well-argued. In the same way as some Masters courses promote 
reflexive thinking (Conkin et al, 2013), the value of critical reflexivity on DBA programmes, even promoting this as a unique selling point, needs to be made a prominent feature in future iterations of DBA programmes at SWAN and elsewhere. In this, co-production and collaboration could be better highlighted and to that end, the paper concludes with recommendations on how that might be achieved.

\section{CONCLUSIONS}

As academics involved in designing and evaluating a DBA programme, the paper's authors have been well positioned to undertake research not simply on but with students (Thomas et al 2009). DBA students were identified earlier in the paper as a critical case for interrogating the value of critical reflexivity at doctoral level insofar as their senior professional standing and non-conventional student status makes them atypical of doctoral students generally. More than this, systematic analysis of student experiences of the DBA has offered a distinct site for academic investigation of critical reflexivity as a collective and collaborative process. This endeavour is important for as Cunliffe (2004) claims: 'critically reflexive practice... is important to management education, because it helps us understand how... we can develop more collaborative and responsive ways of managing organizations' (2004:407 emphasis added).

In addressing the scope for critical reflexivity as a collective process, the paper concludes by offering recommendations for co-production and collaboration in the doctoral research domain. This is not without difficulties because, as the data has shown, the 'logical' development path envisaged by the DBA programme team has not always been straightforward or unproblematic for DBA students. Data analysis has shown how many of them experiencing their 'journey' as one with many confusing directions and routes, made more complex by their contrasting 
cultural and organizationally locations. In the course of writing this paper, the DBA programme team have been working to make improvements to the design, delivery and outcomes of the DBA programme at SWAN by furthering consultation with students. This takes a number of forms. One practical way forward has been to bring the insights from the data analysis to the attention of DBA students who attended a recent block delivery workshop and to encourage them to feedback their responses. The programme team have also committed to making the data analysis available to those students (the questionnaire respondents and the focus group participants) who co-operated with the original request for data, with invitations for them to comment upon the data analysis and the wider arguments presented here. There are also ongoing moves to address the impact of DBA students' research outcomes in novel and various ways, thereby throwing into question conventional notions of what constitutes 'successful' outcomes on the programme. It is our experience that on completion, students graduating from the programme tend to drift away from academic work and few use their thesis to promote or publish any outputs from their work. It may be that their findings impact significantly upon practice, but neither employing organization nor SWAN record this in any way. Notwithstanding, this still raises questions of 'wastage' and we strongly suggest there is a need to promote impact more in terms of conference opportunities (both academic and professionally focused), paper and poster presentations in various forums and, for some, academic journal publication.

In our delivery of the DBA programme over a number of years, the focus has been on the development of the thesis and the submission of the doctorate. In light of the insights gained from the critical reflexive data analysis undertaken and the arguments offered here, meetings are now being held with previous cohorts of DBA students to discuss organizing various forums, including online video blogs, workshops and/or seminars, to showcase the value of 
their research and most importantly, to address its contribution to professional practice. The DBA team have not as yet concluded discussions with current DBA students about what other initiatives would support them as they move towards completion, but that could be a next step in the co-production of significant academic, practitioner-researcher and other professional networking opportunities. The DBA team is also seeking to explore with both previous and current DBA students how and to what effect they have changed their ways of business and organizational working and to make public the findings. Finally, it is clear that programme teams involved in designing and delivering DBAs must be cognisant that developing critically reflexive practitioner-scholars is not a straightforward or rational process. There are clear benefits of programmes of study, even at taught doctoral level, having a 'building block' structure with identifiable goals as milestones. It must, however, be remembered that DBA students will often face significant issues in the development of the necessary critically reflexive skills to assist them in both their practitioner and academic lives. This will always necessitate flexible and sympathetic management of the learning journey by the staff involved in ways that move beyond the 'stage-by-stage' linear development process that was originally assumed.

\section{FUNDING}

This research did not receive any specific grant from funding agencies in the public, commercial, or not-for-profit sectors. 


\section{REFERENCES}

Alvesson M, Hardy C. and Hartley B. (2008) Reflecting on Reflexivity: Reflexive Textual Practices on Organization and Management Theory. Journal of Management Studies 45 (3): $480-501$.

Alvesson M. and Sköldberg K. (2009, $2^{\text {nd }}$ edition) Reflexive Methodology: New vistas for qualitative research. London: Sage.

Bareham J., Bourner T. and Ruggeri-Stevens G. (2000) The DBA: What Is It For? Career Development 5 (7): 394 - 403.

Bettany S.M.M. and Woodruffe-Burton H.R. (2009) Working the limits of method: the possibilities of critical reflexive practice in marketing and consumer research. Journal of Marketing Management 25 (7 - 8): 661 - 680.

Bourner T., Ruggeri-Stevens G. and Bareham J. (2000) The DBA: Form and Function. Education \& Training 42 (9): 481 - 495.

Brooks S. and Coombs H. (2010) Doctor of Business Administration Handbook (DBA and DBA Public Services Management) Unpublished definitive programme document (October 2010) SWAN. 
Conkin J., Kyle T. and Robertson C. (2013) The essential transformation: How Masters students make sense and learn through transformative change. Management Learning 44 (2): 161- 178.

Costley C. and Lester S. (2010). Work-based Doctorates: Professional Extension at the Highest Levels. Studies in Higher Education 32 (3): 257 - 269.

Cunliffe A.L. (2002) Reflexive Dialogical Process. Management Learning 33 (1): 35 - 61.

Cunliffe A.L. (2003) Reflexive inquiry in organizational research: Questions and possibilities. Human Relations 56 (8): 983 - 1003.

Cunliffe A.L (2004) On Becoming A Critically Reflexive Practitioner. Journal of Management Education 28 (4): 407 - 426.

Cunliffe A.L. (2011) Why Complicate a Done Deal? Bringing Reflexivity into Management Research. Cassell C and Lee B (eds.) Challenges and Controversies in Management Research Abingdon Oxon: Routledge.

Dehler G.E, Welsh M.A. and Lewis M.W. (2001) Critical pedagogy in the 'new paradigm': Raising complicated understanding in management learning. Management Learning, 32(4): 493-511. 
Dent E. B. (2002) Developing scholarly practitioners: Doctoral management education in the 21st century. In C. Wankel and R. DeFillippi (Eds.) Rethinking management education for the 21st century Greenwich, CT: Information Age Publishers. 135-155.

Gibb A., Haskins, G. and Robertson I. (2012). Leading the Entrepreneurial University: Meeting the Entrepreneurial Development Needs of Higher Education Institutions. 9 - 45. doi:10.1007/978-1-4614-4590-6_2

Gray D.E. (2007) Facilitating management learning: developing critical reflection through reflexive tools. Management Learning 38 (5): 495 - 517.

Green H. and Powell S. (2005) Doctoral Study in Contemporary Higher Education. Maidenhead: The Society for Research into Higher Education and Open University Press.

Hardy C. and Palmer I (1999) Pedagogical practice and postmodernist ideas. Journal of Management Education 23(4): 377 - 395.

Hardy C., Phillips N. and Clegg S. (2001) Reflexivity in organization and management theory: A study of the production of the research “subject”. Human Relations 54 (5): 531 560. 
Hibbert P., Coupland C. and MacIntosh R. (2010) Reflexivity: recursion and relationality in organizational research processes. Qualitative Research in Organizations and Management: An International Journal 5 (1): 47 - 62.

Isaacs W. (1999) Dialogue: The Art of Thinking Together New York: Doubleday.

Johnson P. and Duberley J. (2003) Reflexivity in Management Research, Journal of Management Studies 40 (5): 1279 - 1303.

Keevers L. and Treleaven L. (2011) Organizing practices of reflection: A practice-based study. Management Learning 45 (5): 505 - 520.

Klenowski V. and Lunt I. (2008) Enhancing learning at doctoral level through the use of reflection. Assessment and Evaluation in Higher Education 33 (2): 203 - 217.

Mauthner N.S. and Doucet A. (2003) Reflexive Accounts and Accounts of Reflexivity in Qualitative Data Analysis. Sociology 37 (3): 413 - 431.

Maxwell T. W. (2008) Professional Doctorates and the DBA in Australia: Retrospect and prospect. Paper presented at the Association of Business Schools Doctorate in Business Administration Annual Conference, Bradford. 
Orr K. and Bennett M. (2009) Reflexivity in the co-production of academic practitioner research. Qualitative Research in Organizations and Management: An International Journal 4 (1): 85 - 102.

Paton S, Chua R. and Burt G. (2014) Relevance or 'relevate'?: How university business schools can add value through reflexively learning from strategic partnerships with business. Management Learning 45 (3): 267 - 288.

Quality Assurance Agency (2008) Discussion Paper About Doctoral Programmes.

Quality Assurance Agency (2011) Doctoral Degree Characteristics.

Quality Assurance Agency (2015) Characteristics Statement UK Quality Code for Higher Education. Part A: Setting and maintaining academic standards Doctoral Degree.

Raelin, J.A. (2002). “I Don’t Have Time to Think!'” Versus the Art of Reflective Practice. Reflections, 4 (1): 66-75.

Raelin, J.A. (2007) Toward an epistemology of practice. Academy of Management Learning and Education, 6 (4): 495-519 
Ramsey, C. (2014). Management learning: A scholarship of practice centred on attention? Management Learning, 45(1), 6-12.

Rhodes C. (2009) After Reflexivity: Ethics and the Writing of Organization Studies. Organization Studies 30 (6): 654 - 672.

Ruggeri-Stevens G., Bareham J. and Bourner T. (2001) The DBA in British Universities: Assessment and Standards. Quality Assurance in Education 9 (2): 61 - 71.

Thomas R., Tienari J., Davies A. and Merilainen S. (2009) Let’s talk about 'Us’: A Reflexive Account of a Cross-Cultural Research Collaboration. Journal of Management Inquiry 18 (4): $313-324$.

Usher R. (2002). A Diversity of Doctorates: Fitness for the Knowledge Economy? Higher Education Research and Development 21 (2): 143 - 153.

Van de Ven A. (2007) Engaged Scholarship: A Guide for Organizational and Social Research Oxford: Oxford University Press.

Vince R. (2002) Organizing reflection. Management Learning 44 (2): 109 - 126. 
Williams W.H. (2010) 'How can doctorates in business and administration contribute to the development of strategists?' Unpublished $\mathrm{PhD}$ thesis, (University anonymised for paper reviewers). 